$\mathrm{BFJ}$

123,13

Received 5 December 2020 Revised 18 March 2021 Accepted 16 April 2021

\section{The satiating power of sustainability: the effect of package sustainability on perceived satiation of healthy food}

\author{
Carmela Donato
}

Department of Business and Management, LUISS Guido Crali, Rome, Italy

Ada Maria Barone

MAPP Centre, Department of Management, Aarhus University, Aarhus V, Denmark, and

Simona Romani

Department of Business and Management, LUISS Guido Crali, Rome, Italy

\begin{abstract}
Purpose - This research investigates the influence of package sustainability on food satiation perception. Design/methodology/approach - Research hypotheses were tested through three experimental studies. Findings - Three experimental studies show that food quality is associated to higher perceived food satiation (preliminary study); that a food packaged in a sustainable package is perceived as more satiating than the same food packaged in a non-sustainable package and that this effect is explained by the higher perceived quality triggered by the presence of a sustainable package (Study 1); and that the positive relationship between higher perceived quality and perceived satiation is verified only for healthy but not for unhealthy foods (Study 2). Originality/value - The present research advances knowledge on the highly debated issue of sustainable food packages. By proposing that consumers might perceive a healthy food presented in a sustainable package as more satiating, the authors show another extrinsic packaging cue modifying consumers' perception, namely package sustainability.
\end{abstract}

Keywords Sustainability, Package, Healthy food, Perceived satiation

Paper type Research paper

\section{Introduction}

Packaging sustainability is an increasing concern for both policymakers, companies and research (Vila-Lopez and Küster-Boluda, 2020), as large amounts of packaging materials produced every year are used and then simply thrown away. In 2017, plastic and glass packaging material, respectively, generated 14.5 million tons and 14 million tons of waste materials in the EU; the same year, $173 \mathrm{~kg}$ of packaging waste per inhabitant were registered [1]. As a result, the European Commission set the goal of replacing all plastic packaging with recyclable materials by 2030 [2]. At the same time, companies are starting to realize that the ability to meet stakeholders' and communities' demands cannot forego the consideration of sustainability issues (Mancini et al., 2017; Steenis et al., 2017; Hoek et al., 2017a), thus recognizing the key role played by packaging in sustainable development. Consequently, retailers such as the French supermarket chain Carrefour are planning to gradually replace

(C) Carmela Donato, Ada Maria Barone and Simona Romani. Published by Emerald Publishing Limited. This article is published under the Creative Commons Attribution (CC BY 4.0) licence. Anyone may reproduce, distribute, translate and create derivative works of this article (for both commercial and noncommercial purposes), subject to full attribution to the original publication and authors. The full terms of this licence may be seen at http://creativecommons.org/licences/by/4.0/legalcode 
non-recyclable plastics by alternative, more environmentally friendly materials [3]. Furthermore, sustainable packaging has been a major topic of discussion in sustainability and marketing literature (e.g., Lindh et al., 2016; Magnier and Crié, 2015; Steenis et al., 2017; Steenis et al., 2018). Indeed, its role is particularly relevant in relation to consumer-packaged goods and especially food.

On this topic, prior research has shown that package is an important information driver in food evaluation, as its shape, color and material implicitly generate inferences about its content in terms of aspects such as taste or calories (e.g., Ares and Deliza, 2010; Becker et al., 2011; Chandon, 2013; Krider et al., 2001, Koo and Suk, 2016; Kunz et al., 2020). Moreover, according to Wansink and Chandon (2006), consumers' expectations about food's ability to satiate their appetite can be modified by the presence of extrinsic cues such as nutrition labels. Conversely, less is known about whether and to what extent other features of food packaging affect consumers' perceptions of satiation. In this sense, as consumers show an increasing concern about green consumption (e.g., Olsen et al., 2014; Magnier and Schoormans, 2015) and their demand for sustainability continues to grow (Kronthal-Sacco and Whelan, 2019), understanding whether package sustainability - in the sense of packages owning intrinsic and/or extrinsic attributes aiming at reducing the product's environmental footprint (Magnier et al., 2016) - affect consumers' perception of satiation and consequently their food consumption appears to be particularly relevant. Few recent papers explored this issue and showed that food presented in packages containing sustainable cues (i.e., logos, color) and food packaged in sustainable packaging are more positively evaluated because of higher perception of quality and naturalness (e.g., Magnier et al., 2016; Marozzo et al., 2020). However, there is no evidence about how packaging sustainability affect consumers' perceived satiation.

Nevertheless, the investigation of this issue must account for the trade-off inherent to the choice between healthy and unhealthy foods (e.g., Talukdar and Lindsey, 2013; Tal and Wansink, 2015; Ivanic, 2016), as consumers believe that healthy food is less satiating than unhealthy alternatives (Finkelstein and Fishbach, 2010; Suher et al., 2016) such that even fastfood meals are believed to be less caloric when advertised as healthy (Chandon and Wansink, 2007). As a result, demand for junk food to the detriment of healthy food choices has been growing in recent years (Fryar et al., 2018), with obesity increasing from $11.7 \%$ in 2012 to $13.2 \%$ in 2016, and with a total of 2.6 billion of people being overweight globally in 2018 (FAO, 2018) [4].

Hence, building on evidence about the effect of package sustainability on consumers' perceptions (e.g., Magnier et al., 2016) and on results from prior research showing that extrinsic cues affect satiation perceptions (i.e., Wansink et al., 2004; Miraballes et al., 2014), we argue that food packaged in a sustainable (vs. not sustainable) package is perceived as more satiating than food presented in a non-sustainable package. More specifically, we argue that this effect is a halo effect deriving from higher perceptions of food quality associated with the use of a sustainable package.

However, based on Cue Consistency Theory - according to which under uncertainty consumers are more likely to rely during their evaluations on the presence of multiple cues providing corroborating (vs. disparate) information (Maheswaran and Chaiken, 1991) - we argue and demonstrate that this effect holds only for healthy (vs. unhealthy) foods. Thus, through this research we build on and contribute to the literature on how consumers use packaging to make inferences about food content, finding another source of food estimation bias, i.e., package sustainability. In doing so, we conducted three experimental studies with the objective of testing the proposed causal relationship between package sustainability and perceived food satiation.

The remainder of this paper is organized as follows. First, we discuss how package sustainability positively influences perceived food satiation via food quality and present the 
BFJ

123,13

associated hypotheses. Second, we present three empirical studies aimed at testing the hypothesized mechanism. Finally, we conclude with discussion of findings and presentation of implications for managers and policymakers.

\section{Conceptual framework}

\subsection{Package sustainability and food satiation}

Product packaging serves multiple logistical functions, including simplified transportation of goods, efficient product storage and product protection (Rundh, 2005). Packaging is also acknowledged as an important tool in the marketing communications strategy, through the transmission of information about product benefits, the construction and/or the reinforcement of the brand image, and the supply of visual cues that facilitate associations with other elements of the communications mix (e.g., Underwood and Klein, 2002). However, product packaging is also one of the main contributors to municipal solid waste (EPA, 2019), with detrimental effects on the environment (Hall, 2017). This suggests the need for more sustainable solutions, in the sense of packaging production and development, whereby the needs of the present generation will not compromise the ability of future generations to meet their own needs [5] and with new packages developed consistently with the goals of sustainable development, from cradle to grave (Martinho et al., 2015). At the same time, this shift raises the question of how and to what extent these new solutions affect consumers' perception. As a result, several authors (e.g., Magnier and Crié, 2015; Magnier and Schoormans, 2015; Magnier et al., 2016; Seo and Scammon, 2017; Steenis et al., 2017; Rees et al., 2018; Ketelsen et al., 2020) have recently focused their efforts on the understanding of the effect of package sustainability on consumers' perceptions and evaluations of the related packaged products. More specifically, sustainable packages have been defined as packages evoking via their structure or graphical elements eco-friendliness to customers, as for example through the usage of biodegradable materials, or eco-friendly logos (Magnier and Crié, 2015). In this sense, a sustainable package - e.g., a paper-based package entirely made from biodegradable material - is expected to be beneficial, safe and healthy for individuals and communities throughout its life cycle [6]. Coherently, a consistent stream of consumer research highlights that the usage of more sustainable packages positively influences consumers' attitude and choice behavior (Martinho et al., 2015; Prakash and Pathak, 2017; Rokka and Uusitalo, 2008; Van Biergelen et al., 2009; Rees et al., 2019) and that packages sustainability can affect consumers' likelihood of purchase and willingness to pay (Magnier and Schoormans, 2015; Nordin and Selke, 2010; Pancer et al., 2017).

The usage of sustainable packages also plays a key role in consumers' perceptions of food, not only for their primary functions such as food preservation and transportation, but also because they allow consumers to draw inferences about the product or its attributes using both intrinsic (e.g., labels and logos) and extrinsic (e.g., package material; Magnier et al., 2016) attributes. For example, Van Birgelen et al. (2009) showed that consumers are willing to trade off almost all products attributes, except for taste and price, in favor of environmentally friendly packaging. In the same vein, Lee et al. (2013) and Magnier et al. (2016) demonstrated that the perceived quality of food products is more positive when they are packaged in a sustainable packaging. Moreover, Marozzo et al. (2020) found that packages that adopt au naturel colors evoking natural elements (i.e., beige) increase perceptions of products authenticity, and therefore higher consumers' willingness to pay. According to previous research (Huber and McCann, 1982; Pinson, 1986), consumers are not aware about these inferences, as they implicitly transfer the impressions generated from one element (i.e., packaging material) to another (i.e., packaged food). Building on these findings we propose another food estimation bias generated by the usage of sustainable packages. More 
specifically, we argue that food packages that signal sustainability using extrinsic properties such as material (i.e., beige paper-based) positively influence the perception of food satiation.

Food satiation can be defined as resulting from the "associative learning between the food's sensory properties, mainly the visual cues, and the remembered satiation after eating" (Labbe et al., 2017, p. 311). Previous research found that perceived food satiation is strongly correlated with the perceived food energetic content (Brunstrom and Rogers, 2009; Brunstrom and Shakeshaft, 2009), and with food familiarity (Brunstrom et al., 2008) but also with unrelated food factors such as nutrition labels (e.g., Miraballes et al., 2014). In this research, we propose and investigate a novel extrinsic attribute influencing consumers' perceived food satiation, namely package sustainability.

In particular, we propose that consumers transfer a higher capability to satiate their appetite to foods presented in a sustainable (vs. non-sustainable) package. We posit that this effect is a halo effect of the higher perceived quality that consumers attribute to food packaged in sustainable packages. As extensively shown by prior research (e.g., Chandon and Wanskink, 2007; Schuldt et al., 2012; Sundar and Kardes, 2015), the halo effect is the phenomenon in which the presence of an external cue leads consumers to form favorable overall evaluations of a product, which in turn guides inferences about specific missing or unknown attributes. Similarly, we propose that consumers form a higher quality evaluation toward food presented in sustainable packages (i.e., external cues), which in turn leads to inferences about perceived satiation. More specifically, we propose that the higher quality attributed to the food presented in a sustainable package (Magnier et al., 2016) will unconsciously lead consumers to misattribute a higher food satiation capability to the food. In this sense, the superior quality deriving from the presence of the sustainable package is implicitly translated into a perception of satiation. Conversely, this effect does not hold for food presented in a non-sustainable package as the non-sustainable package is not associated to superior food quality; as a result, the implicit satiation association will not be perceived. It is important to note that the perceived superior food quality that does not derive from a sustainable package (i.e., external cue) is not able to generate a satiation halo effect, because consumers consciously attribute the perceived quality to food properties, and as a result, they are conscious about the food ability to satiate their appetite. Formally:

H1. Food packaged in a sustainable (vs. non-sustainable) package is perceived as more satiating due to the higher quality attributed to the food packaged in a sustainable package.

\subsection{The moderating role of food healthiness}

In practice, sustainable packages often protect healthy foods (e.g., fruit, vegetables), that generally are perceived as less satiating than unhealthy foods (e.g., junk food; Finkelstein and Fishbach, 2010; Suher et al., 2016; Raghunathan et al., 2006). Building on Cue Consistency Theory (CCT, Maheswaran and Chaiken, 1991), we propose that the misperception of package sustainability on perceived food satiation holds only for healthy (vs. unhealthy) foods. CCT theory states that in low motivation situations, as those situations involving food purchases (Dahlèn et al., 2000), consumers use both high (i.e., systematic) and low (i.e., heuristic) diagnostic cues for processing product quality. When the cues are both congruent in their communication, subjects engage in an additive evaluation process; when the cues are not congruent (i.e., one is positive, the other is negative), an attenuation evaluation processing takes place.

We argue that sustainable package and healthy food are perceived as congruent cues by consumers: first, because they are both virtuous cues (Hoek et al., 2017b); second, because in practice healthy foods are often packaged in sustainable packages. Indeed, whereas plastic and functional packaging is needed to preserve the nutritional quality of products such as 
$\mathrm{BFJ}$

123,13

166

Figure 1.

Theoretical framework meat and regular produce, organic and high-quality produce is commonly sold in supermarkets in sustainable packages such as paper-based bags. Similarly, sustainable packaging is commonly used to suggest healthiness when selling snacks rich in fat and with poor nutritional quality. All these evidences strengthen the implicit association between sustainable package and healthy foods. Finally, the combination of healthy food and sustainable packages can often be observed in the activities of organic retailers; this is, for instance, the case of the Dutch supermarket chain Ekoplaza, that in 2018 opened a plastic-free pop-up store offering more than 700 organic food packaged using more sustainable materials [7].

We argue that while the presence of a sustainable package will improve the perceived quality of both healthy and unhealthy food, the halo effect of perceived quality on perceived satiation will be verified only for food that is conceptually congruent (vs. non-congruent) with sustainable package. Therefore, we expect an additive evaluation process to occur only for healthy foods presented in sustainable packages, such that the higher perceived quality deriving from the presence of a sustainable package will lead to perceptions of higher satiation. Conversely, sustainable packages and unhealthy foods are not conceptually congruent (i.e., in terms of the extent to which they can be perceived as virtuous cues the sustainable package has a positive valence, the unhealthy food has a negative valence); as a result, an attenuation evaluation process will take place such that the higher perceived quality determined by the sustainable package will not result in a higher perceived satiation (see Figure 1). Formally:

H2. The higher perceived quality generated by the presence of a sustainable (vs. nonsustainable) package on perceived satiation holds only for healthy foods. For unhealthy foods the usage of a sustainable (vs. non-sustainable) package does not generate differences in terms of perceived satiation.

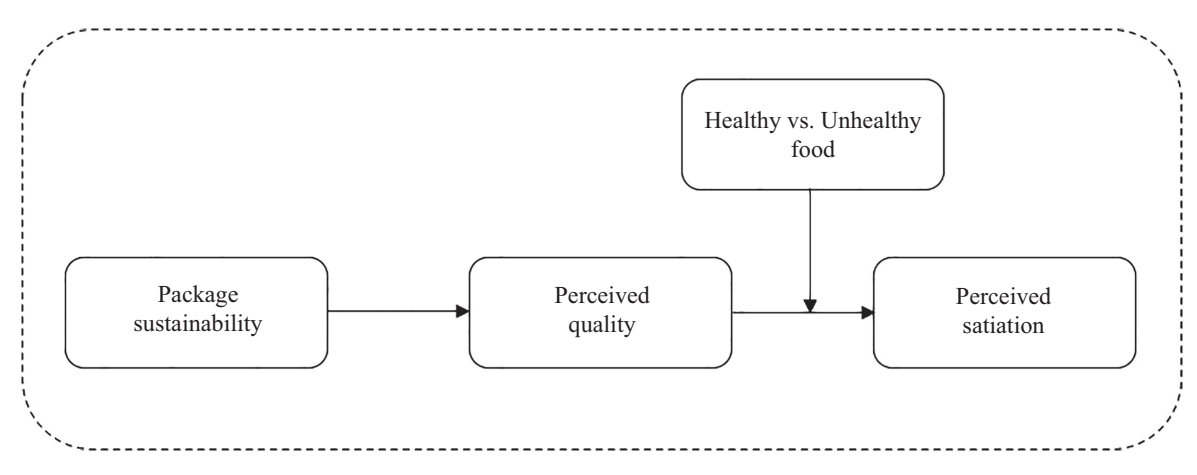

\section{Method}

We tested our conceptual framework in three experimental studies. First, a preliminary study was conducted to gain some insights about the proposed halo effect of food quality on perceived satiation. Second, Study 1 tested H1, whereas Study 2 tested H2. In each study, package sustainability was operationalized by manipulating the package material (paper vs. plastic-based). Package shape was varied in each experiment to rule out possible alternative explanations related to package shape.

\subsection{Preliminary study}

We conducted a preliminary study to gain initial evidence of our rationale, that is that of the proposed relationship between food quality and perceived food satiation. More specifically, 
we asked 72 subjects $\left(58 \%\right.$ female; $\left.M_{\text {age }}=31.80, \mathrm{SD}=8.45\right)$ recruited through a social network to first indicate in their opinion what are the characteristics of a satiating food. Then, they were explicitly asked to rate the extent to which they perceived a high-quality food and a food packaged in a sustainable package respectively as satiating $(1=$ not at all; $7=$ a lot). Coding of the provided answers it was found that indeed participants believe that satiating foods should be of high quality (39.1\%), should have several nutrients (e.g., vitamins, proteins, carbohydrates), should be provided in high quantity (21.7\%), should be tasty $(39.1 \%)$ and should be rich of calories $(7.2 \%)$. Moreover, in line with our expectations, results of a pair-sample $t$-test revealed that participants on average perceived a high quality food as more satiating than a food packaged in a sustainable package $\left(M_{\text {quality }}=4.47, \mathrm{SD}=1.52\right.$, $M_{\text {sust_pack }}=4.03, \mathrm{SD}=1.50, t(71)=2.53, p=0.01$ ), giving therefore a first confirmation to our hypothesis.

\subsection{Study 1}

Study 1 was aimed at providing evidence for $\mathrm{H} 1$, demonstrating that the use of a sustainable (vs. non-sustainable) food package increases consumers' perceived satiation via higher perceived quality.

Eighty-one volunteers ( $58 \%$ female; $\left.M_{\text {age }}=27.11, \mathrm{SD}=11.11\right)$ recruited by a research assistant through a snowball sampling procedure were randomly assigned to one of two conditions within a two-cell, between-subjects experiment. Specifically, participants were informed that they had to evaluate a snack offered by an anonymous cafeteria and depending on the condition they were exposed to a Turkey Sandwich packaged in a sustainable vs. a non-sustainable package. In both conditions, the Sandwich was presented with a list of ingredients (i.e., grilled Turkey, salad, low-fat cheese) and presented in the same package shape (i.e., a triangular Sandwich container), but with a different material (i.e., paper vs. plastic-based, see Appendix 1).

After the experimental stimuli exposure, we asked participants to rate the extent to which they perceived the Sandwich to be able to satiate their appetite ( $1=$ "not at all", $7=$ "a lot"). Our proposed mediator - perceived quality - was measured using two items from White et al. (2016). More specifically, participants were asked to rate the extent to which they perceived the Sandwich to have bad/good quality and low/high quality on a seven-points scale $(r=0.71$, $M=4.76, \mathrm{SD}=1.29)$. Manipulation check measures were also administered asking participants to rate the extent to which they perceived the package containing the snack shown at the beginning of the study as sustainable ( $1=$ "not at all"; $7=$ "a lot"), and the extent to which they perceived the snack (Turkey Sandwich) as healthy ( $1=$ "not at all"; 7 = "a lot"). Finally, demographic information (age and gender) was collected and participants were debriefed and thanked for their participation.

3.2.1 Results. Results of two independent sample $t$-tests showed that the manipulation was successful, as the paper-based package was perceived as significantly more sustainable than the plastic package $\left(M_{\text {sust }}=5.46, \mathrm{SD}=1.36\right.$ vs. $M_{\text {nonsust }}=2.25, \mathrm{SD}=1.37, t(79)=10.57$, $p<0.001$ ) while there was no difference in terms of perceived healthiness between the two conditions $\left(M_{\text {sust }}=4.59, \mathrm{SD}=1.34\right.$ vs. $\left.M_{\text {nonsust }}=4.35, \mathrm{SD}=1.08, t(79)=0.87, p=n s\right)$. We conducted mediation analysis (Model 4 of PROCESS macro; Hayes, 2013) to test H1 wherein package sustainability ( $0=$ not sustainable; $1=$ sustainable) predicted perceived food quality, which in turn predicted perceived satiation. The results revealed that package sustainability positively affected perceived food quality $(b=0.86$, se $=0.27 ; t=3.16$, $p<0.01)$, which then positively affected perceived satiation $(b=0.36$, se $=0.09 ; t=3.62$, $p<0.001)$. The direct effect of package sustainability on perceived food perceived satiation was not significant $(b=-0.21$, boot standard error $[\mathrm{SE}]=0.25 ; 95 \%$ confidence interval $[C \Gamma]=-0.71 ; 0.29)$. However, the indirect effect of package sustainability on perceived food
The satiating power of sustainability 
$\mathrm{BFJ}$ 123,13

Figure 2

Results of Study 1

\section{8}

satiation turned out to be statistically significant $(b=0.31$, boot standard error $[\mathrm{SE}]=0.13$; $95 \%[\mathrm{CI}]=0.09 ; 0.62$ ). As a consequence, findings of Study 1 provide full support to H1, showing that using sustainable packages leads to higher perceptions of food quality and, in turn, to higher perception of satiation compared to using non-sustainable packages (see Figure 2).

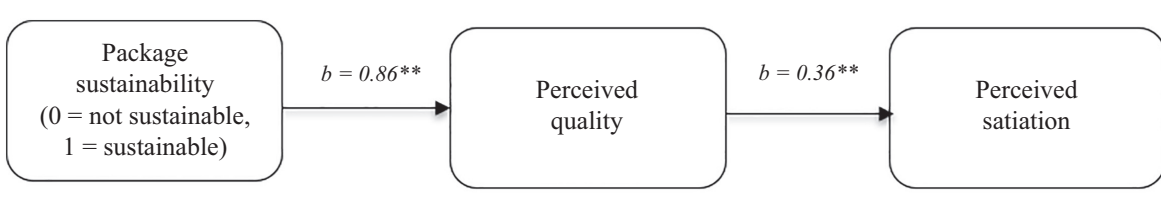

Indirect effect $\rightarrow b=0.31[0.09 ; 0.62]$

\subsection{Study 2}

The aim of Study 2 was to test H2, according to which the halo effect resulting from the higher perceived quality generated by the presence of a sustainable package on perceived satiation holds only for healthy and not for unhealthy foods.

Two hundred and four volunteers ( $49 \%$ female; $\left.M_{\text {age }}=36.31, \mathrm{SD}=13.35\right)$ recruited by a research assistant through a snowball sampling procedure were randomly assigned to one of four conditions within a four-cell between-subjects experiment in which package material (sustainable vs. non-sustainable) and food healthiness (low: French fries vs. high: apple salad) were manipulated. The package manipulation was very similar to the one used in the previous study, except for the shape that in this case was squared (see Appendix 2). Similar to Study 1, participants were informed that they had to evaluate a snack offered by an anonymous cafeteria, then depending on the conditions they were randomly assigned to one of four scenarios: the picture of a sustainable (i.e., paper-based) package containing either an apple salad or French fries, and a picture of a non-sustainable (i.e., plastic) package containing either an apple salad or French fries. In each condition the same package shape (i.e., a squared bowl) was used, with only the material of the package (i.e., paper-based vs. plastic) being different across the sustainable and non-sustainable conditions. Moreover, in each condition we informed participants about the food weight (250 gr., see Appendix 2).

After being shown the stimulus, participants were asked to rate the extent to which they perceived the snack as able to satiate their appetite $(1=$ "not at all", $7=$ "a lot"), to rate perceived food quality using the two items used in previous studies (adapted from White et al., 2016; $r=0.84 ; M=5.06, \mathrm{SD}=1.57)$. Then, we administered manipulation checks asking participants to rate the extent to which they perceived the package containing the snack as sustainable ( $1=$ "not at all"; $7=$ "a lot"), and the extent to which they perceived the snack shown at the beginning of the study as healthy ( $1=$ "not at all"; $7=$ "a lot"). Finally, demographic information (age and gender) was collected and participants were debriefed and thanked for their participation.

3.3.1 Results. Results of two independent sample $t$-tests showed that both manipulations were successful, as participants in the sustainable package conditions perceived the package as significantly more sustainable than participants in the non-sustainable package conditions $\left(M_{\text {sust }}=6.42, \mathrm{SD}=1.24\right.$ vs. $\left.M_{\text {nonsust }}=1.53, \mathrm{SD}=1.05 ; t(202)=30.31, p<0.001\right)$, while participants in the healthy food conditions perceived the snack (i.e., apple salad) as significantly healthier than participants in the unhealthy food (i.e., French fries) conditions $\left(M_{\text {healthy }}=5.66, \mathrm{SD}=1.45\right.$ vs. $\left.M_{\text {unhealthy }}=2.25, \mathrm{SD}=1.33 ; t(202)=17.43, p<0.001\right)$. We then conducted a two-way ANOVA on perceived food satiation in order to provide first evidence to 
our conceptualization, namely that the proposed halo effect is verified only for healthy (i.e., apple salad) and not for unhealthy food (i.e., French fries). Results revealed a significant effect of package sustainability $\left(M_{\text {sust }}=4.13, \mathrm{SD}=1.39\right.$ vs. $M_{\text {nonsust }}=3.67$, $\mathrm{SD}=1.64$; $F(1,199)=3.80, p=0.05)$ and food healthiness $\left(M_{\text {healthy }}=3.52, \mathrm{SD}=1.38\right.$ vs. $\left.M_{\text {unhealthy }}=4.31, \mathrm{SD}=1.58 ; F(1,199)=14.43, p<0.001\right)$ on satiation, showing respectively that food packaged in a sustainable package is perceived as more satiating and that French fries are on average perceived as more satiating than apple salad. More importantly, the main effects were qualified by a significant interaction between the two independent variables $(F(1,199)=10.34, p<0.01)$. Coherently with $\mathrm{H} 2$, planned comparisons indicated that for healthy foods consumer perceived satiation is higher when they are served in a sustainable package $\left(M_{\text {sust_healthy }}=4.00, \mathrm{SD}=1.32 \mathrm{vs}\right.$. $M_{\text {nonsust_healthy }}=3.08, \mathrm{SD}=1.28$; $F(1,199)=14.43, p<0.001)$, whereas for unhealthy foods there is no significant difference in terms of consumer perceived satiation $\left(M_{\text {sust_unhealthy }}=4.25, \mathrm{SD}=1.44\right.$ vs. $M_{\text {nonsust_unhealthy }}=4.38, \mathrm{SD}=1.75 ; F(1,199)=0.19, p<$ ns; see Figure 3$)$.

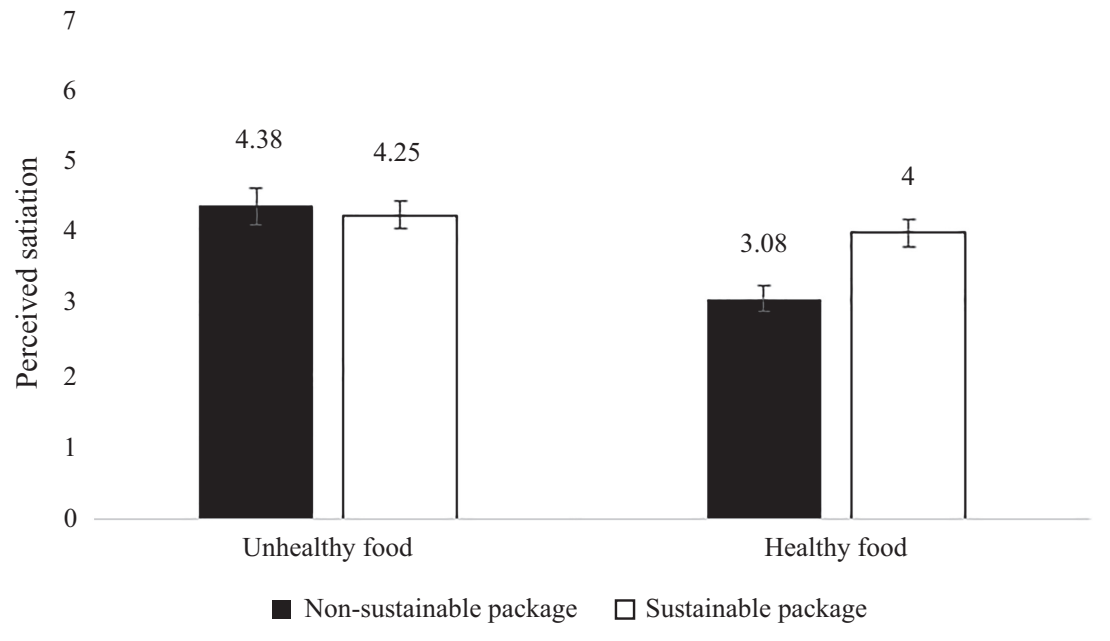

The satiating power of sustainability

Then we conducted a moderated-mediation analysis (Model 14 in PROCESS, Hayes, 2013), with package sustainability as independent variable $(0=$ non-sustainable, $1=$ sustainable $)$, perceived food satiation as dependent variable, perceived food quality as mediator, and food healthiness as moderator ( $0=$ healthy, $1=$ unhealthy). The results showed that package sustainability positively influences food perceived quality $(b=1.71, t=9.23, p<0.001)$. Moreover, both perceived food quality $(b=0.54, t=5.24, p<0.001)$ and food healthiness $(b=2.76, t=4.14, p<0.001)$ positively influences perceived food satiation, whereas package sustainability does not $(b=-0.22, t=-0.93, p=\mathrm{ns})$. However, coherently with $\mathrm{H} 2$ the effect of the interaction between perceived food quality and food healthiness resulted to be significant $(b=-0.36, t=-2.87, p<0.01)$, with a significant moderated mediation index $(b=-0.62,[\mathrm{CI}]=-1.13,-0.19)$. More importantly, an analysis of the conditional indirect effects showed that perceived food quality significantly mediated the effect of package sustainability on perceived food satiation for healthy food $(b=0.95$, boot $\mathrm{SE}=0.19,95 \%$ $[$ C.I. $]=0.61,1.35)$, but not for unhealthy ones $(b=0.31$, boot $\mathrm{SE}=0.21,95 \%[\mathrm{CI}]=-0.11$, 0.73; see Figure 4). 


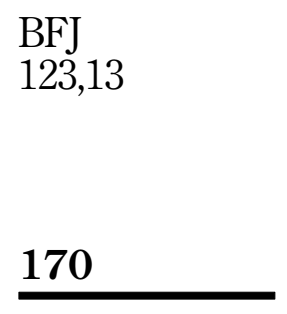

Figure 4.

Results of Study 2

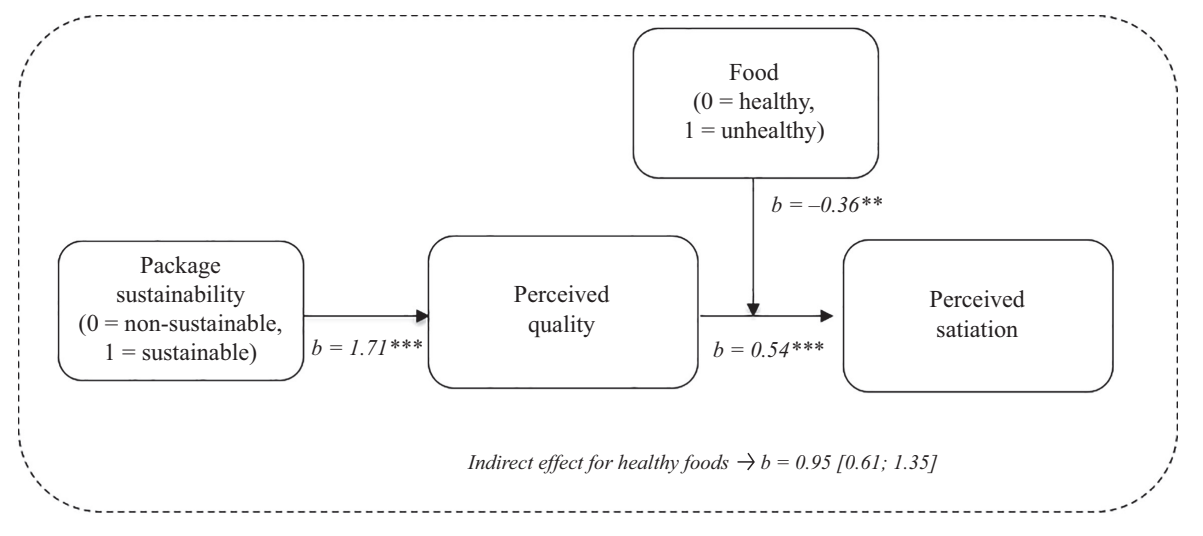

Findings from study 2 corroborate results of Study 1 according to which the higher perceived quality deriving from the usage of a sustainable package increases consumers' perceived food satiation. Furthermore, coherently with $\mathrm{H} 2$, these results hold only for foods that are perceived as healthy by consumers, whereas for those foods that are perceived as unhealthy the higher perceived quality deriving from the usage of a sustainable package does not lead to higher perceived satiation.

\section{General discussion}

Across three studies, we showed that the use of sustainable food packages generates a halo effect such that food packaged in sustainable packages (e.g., paper) is perceived to be more satiating than the same food packaged in non-sustainable packages (e.g., plastic), and consistently with results from prior research (Magnier et al., 2016), we show that this effect is driven by perceptions of higher quality associated with food packaged in sustainable packages. Finally, we provide robust evidence that our hypothesized halo effect is verified only for healthy foods. Indeed, whereas both healthy and unhealthy foods are perceived to have higher quality when packaged in sustainable (vs. non-sustainable) packages, only healthy food is perceived to be more satiating. Building on findings from CCT theory (Maheswaran and Chaiken, 1991), we argue that this is the result of an additive evaluation process taking place because both sustainability and healthiness are perceived as coherent virtuous external cues, leading consumers to misattribute to the healthy food a higher ability to satiate their appetite. Conversely, this process does not occur for unhealthy foods, as the unhealthiness of the food is not a virtuous cue.

This paper significantly contributes to a better understanding of a research area that has been largely neglected by prior research, namely consumers' responses toward sustainable food packages. Indeed, our research extends results from Magnier et al. (2016) by showing that the higher perceived quality associated with package sustainability increases healthy food perceived ability to satiate consumers' appetite. In this sense, we add to this stream of literature by identifying a novel downstream effect of package sustainability, that is, perceived satiation. Furthermore, we contribute to literature on how package characteristics impact consumers' food perception and behavior (e.g., Deng and Srinivasan, 2013; Scott et al., 2008) by focusing on another, largely unexplored, extrinsic package characteristic, that is, package sustainability. Finally, we add to work exploring how marketing factors and psychological processes affect perceptions of food satiation (e.g., Galak et al., 2014; PiquerasFiszman and Spence, 2012; Suher et al., 2016; Fiszman et al., 2014). 
At the practical level, our research provides useful recommendations for both companies in terms of package design and policymakers. Indeed, buying food is one of the most common activities consumers pursue several times each day, from selecting their lunches or snacks during their work breaks, to grocery shopping. Most of the time these apparently common activities involve several conflicting desires such as the trade-off between unhealthy and healthy alternatives, with the latter generally perceived as less satiating than the former. Consumers' implicit belief that healthy foods are less satiating than unhealthy ones has a twofold negative impact: on the one hand, this belief can lead consumers to choose unhealthy foods over healthier foods, with long-term effects on the individual's health and well-being; on the other hand, it might lead to the paradoxical overconsumption of foods that are perceived as healthy (e.g., Chandon and Wansink, 2007; Wansink and Chandon, 2006). Our results about sustainable packages increasing the perceived ability of healthy foods to satiate consumers' appetite provide an easy solution to these issues to be potentially implemented by both companies promoting healthy eating and policymakers. For instance, food manufacturers and retailers selling healthy food should market healthy foods in sustainable packages (e.g., paperbased) rather than in more traditional, non-sustainable materials such as plastic. Indeed, this solution would increase both consumers' likelihood of choosing healthy foods and the perceived quality of the food, with potential positive consequences for the seller image. Furthermore, our results support the economic convenience of adopting sustainable packaging for selling healthy food. Indeed, while consumers' belief that healthy foods are less satiating than unhealthy ones may lead consumers to choose the latter over the former, we show that sustainable packages overcome this belief, meaning that the perceived satiation of healthy food could be boosted by simply changing the material (sustainable vs. non-sustainable) in which they are packaged. Similarly, policymakers could design directives and regulations for the promotion of healthy eating taking into account package materials. Furthermore, our results show that the positive effect of sustainable packaging on perceived quality holds for unhealthy foods as well; this suggests that the overarching beneficial effects of choosing this route as the quality of food packaged in sustainable materials is more positively evaluated regardless of the food category (healthy vs. unhealthy). From a public policy perspective, our findings about package sustainability and food satiation for healthy food is a pivotal result as it provides policymakers with an unobtrusive and easily manipulation tool to promote consumption of healthy foods.

Considering the environmental challenges that society has to face and the need to develop sales of sustainable products and to promote healthy diet, the relationship between sustainability and healthy foods is a fertile topic for future research. Further research could aim to confirm our results considering different operationalization of healthy (vs. unhealthy) foods (e.g., vice and virtue), or manipulating the number of foods ingredients. Moreover, in our studies we operationalized packaging sustainability as paper-based materials and we did not test for the effect of other sustainable materials such as recycled plastic, or fiber-based materials. Future research could verify if our results can be extended also to alternative sustainable materials. Moreover, we considered only beige paper-based packages without considering whether our results hold also for other package colors (i.e., white paper). Additionally, our studies did not take into account two important variables that could affect both quality and satiation perceptions, namely consumers' knowledge about food nutrition and their educational level. It is possible that the effect shown in our studies is stronger for consumers low in food nutritional knowledge; hence, future research could consider the moderating role of food consumers' knowledge, while controlling for consumer's educational level. Another possible avenue worth investigating by future research is the effect that package sustainability has on the perception of unhealthy food. While our results did not find any effect in terms of food satiation, there might be other processes at play that could impact the way consumers perceive or behave towards unhealthy foods. Finally, further research 
$\mathrm{BFJ}$ 123,13

could verify the role of attractiveness in the relationship between package sustainability and perceived food satiation.

\section{Notes}

1. https://ec.europa.eu/eurostat/statistics-explained/index.php/Packaging_waste_statistics

2. https:/ec.europa.eu/environment/circular-economy/pdf/plastics-strategy-brochure.pdf

3. http://www.carrefour.com/sites/default/files/carrefours_environmental_management_policy_en_ 2017.pdf

4. http://www.fao.org/news/story/en/item/1152439/icode/

5. https://sustainabledevelopment.un.org/content/documents/5987our-common-future.pdf

6. https://sustainablepackaging.org/wp-content/uploads/2017/09/Definition-of-SustainablePackaging.pdf

7. https://www.packagingdigest.com/sustainable-packaging/the-emergence-of-the-plastics-freegrocery-aisle-2018-04-30

\section{References}

Ares, G. and Deliza, R. (2010), "Studying the influence of package shape and colour on consumer expectations of milk desserts using word association and conjoint analysis", Food Quality and Preference, Vol. 21 No. 8, pp. 930-937.

Becker, L., van Rompay, T.J., Schifferstein, H.N. and Galetzka, M. (2011), "Tough package, strong taste: the influence of packaging design on taste impressions and product evaluations", Food Quality and Preference, Vol. 22 No. 1, pp. 17-23.

Brunstrom, J.M. and Rogers, P.J. (2009), "How many calories are on our plate? Expected fullness, not liking, determines meal-size selection”, Obesity, Vol. 17 No. 10, pp. 1884-1890.

Brunstrom, J.M. and Shakeshaft, N.G. (2009), "Measuring affective (liking) and non-affective (expected satiety) determinants of portion size and food reward", Appetite, Vol. 52 No. 1, pp. 108-114.

Brunstrom, J.M., Shakeshaft, N.G. and Scott-Samuel, N.E. (2008), "Measuring 'expected satiety' in a range of common foods using a method of constant stimuli", Appetite, Vol. 51 No. 3, pp. 604-614.

Chandon, P. (2013), "How package design and packaged-based marketing claims lead to overeating", Applied Economic Perspectives and Policy, Vol. 35 No. 1, pp. 7-31.

Chandon, P. and Wansink, B. (2007), "The biasing health halos of fast-food restaurant health claims: lower calorie estimates and higher side-dish consumption intentions", Journal of Consumer Research, Vol. 34 No. 3, pp. 301-314.

Dahlèn, M., Ekborn, Y. and Mörner, N. (2000), "To click or not to click: an empirical study of response to banner ads for high and low involvement products", Consumption, Markets and Culture, Vol. 4 No. 1, pp. 57-76.

Deng, X. and Srinivasan, R. (2013), "When do transparent packages increase (or decrease) food consumption?”, Journal of Marketing, Vol. 77 No. 4, pp. 104-117.

EPA (2019), Containers and Packaging: Product-specific Data, available at: https://www.epa.gov/factsand-figures-about-materials-waste-and-recycling/containers-and-packaging-product-specificdata (accessed 20 May 2020).

Finkelstein, S.R. and Fishbach, A. (2010), "When healthy food makes you hungry", Journal of Consumer Research, Vol. 37 No. 3, pp. 357-367.

Fiszman, S., Varela, P., Díaz, P., Linares, M.B. and Garrido, M.D. (2014), "What is satiating? Consumer perceptions of satiating foods and expected satiety of protein-based meals", Food Research International, Vol. 62, pp. 551-560. 
Fryar, C.D., Hughes, J.P., Herrick, K.A. and Ahluwalia, N. (2018), Fast Food Consumption Among Adults in the United States, 2013-2016, NCHS Data Brief, No. 322, October.

Galak, J., Redden, J.P., Yang, Y. and Kyung, E.J. (2014), "How perceptions of temporal distance influence satiation”, Journal of Experimental Social Psychology, Vol. 52, pp. 118-123.

Hall (2017), Throwaway Culture Has Spread Packaging Waste Worldwide: Here's what to Do about it, available at: https:/www.theguardian.com/environment/2017/mar/13/waste-plastic-foodpackaging-recycling-throwaway-culture-dave-hall (accessed 16 June 2020).

Hayes, A.F. (2013), "Mediation, moderation, and conditional process analysis", Introduction to Mediation, Moderation, and Conditional Process Analysis: A Regression-Based Approach edn, Guilford Publications, New York, pp. 1-20.

Hoek, A.C., Pearson, D., James, S.W., Lawrence, M.A. and Friel, S. (2017a), "Healthy and environmentally sustainable food choices: consumer responses to point-of-purchase actions", Food Quality and Preference, Vol. 58, pp. 94-106.

Hoek, A.C., Pearson, D., James, S.W., Lawrence, M.A. and Friel, S. (2017b), "Shrinking the food-print: a qualitative study into consumer perceptions, experiences and attitudes towards healthy and environmentally friendly food behaviours", Appetite, Vol. 108, pp. 117-131.

Huber, J. and McCann, J. (1982), "The impact of inferential beliefs on product evaluations", Journal of Marketing Research, Vol. 19 No. 3, pp. 324-333.

Ivanic, A.S. (2016), "To choose (not) to eat healthy: social norms, self-affirmation, and food choice", Psychology and Marketing, Vol. 33 No. 8, pp. 595-607.

Ketelsen, M., Janssen, M. and Hamm, U. (2020), “Consumers' response to environmentally-friendly food packaging-a systematic review”, Journal of Cleaner Production, Vol. 254, pp. 120-123.

Koo, J. and Suk, K. (2016), “The effect of package shape on calorie estimation”, International Journal of Research in Marketing, Vol. 33 No. 4, pp. 856-867.

Krider, R.E., Raghubir, P. and Krishna, A. (2001), "Pizzas: $\pi$ or square? Psychophysical biases in area comparisons", Marketing Science, Vol. 20 No. 4, pp. 405-425.

Kronthal-Sacco, R. and Whelan, T. (2019), Sustainable Share Index ${ }^{\text {TM}}$ : Research on IRI Purchasing Data (2013-2018), available at: https:/www.stern.nyu.edu/sites/default/files/assets/documents/ NYUSternCSB_Sustainab leShareIndex_2019. pdf.

Kunz, S., Haasova, S. and Florack, A. (2020), "Fifty shades of food: the influence of package color saturation on health and taste in consumer judgments", Psychology and Marketing, Vol. 37 No. 7, pp. 900-912.

Labbe, D., Rytz, A., Godinot, N., Ferrage, A. and Martin, N. (2017), "Is portion size selection associated with expected satiation, perceived healthfulness or expected tastiness? A case study on pizza using a photograph-based computer task", Appetite, Vol. 108, pp. 311-316.

Lee, W.C.J., Shimizu, M., Kniffin, K.M. and Wansink, B. (2013), "You taste what you see: do organic labels bias taste perceptions?”, Food Quality and Preference, Vol. 29 No. 1, pp. 33-39.

Lindh, H., Olsoon, A. and Williams, H. (2016), "Double standard: the role of environmental consciousness in green product usage", Journal of Marketing, Vol. 76 No. 5, pp. 125-134.

Magnier, L. and Crié, D. (2015), "Communicating packaging eco-friendliness: an exploration of consumers' perceptions of eco-designed packaging", International Journal of Retail and Distribution Management, Vol. 43 Nos 4-5, pp. 350-366.

Magnier, L. and Schoormans, J. (2015), "Consumer reactions to sustainable packaging: the interplay of visual appearance, verbal claim and environmental concern", Journal of Environmental Psychology, Vol. 44, pp. 53-62.

Magnier, L., Schoormans, J. and Mugge, R. (2016), "Judging a product by its cover: packaging sustainability and perceptions of quality in food products", Food Quality and Preference, Vol. 53, pp. 132-142.

The satiating power of sustainability 
BFJ

123,13

Maheswaran, D. and Chaiken, S. (1991), "Promoting systematic processing in low-motivation settings: effect of incongruent information on processing and judgment", Journal of Personality and Social Psychology, Vol. 61 No. 1, p. 13.

Mancini, P., Marchini, A. and Simeone, M. (2017), "Which are the sustainable attributes affecting the real consumption behaviour? Consumer understanding and choices", British Food Journal, Vol. 119 No. 8, pp. 1839-1853.

Martinho, G., Pires, A., Portela, G. and Fonseca, M. (2015), "Factors affecting consumers' choices concerning sustainable packaging during product purchase and recycling", Resources, Conservation and Recycling, Vol. 103, pp. 58-68.

Marozzo, V., Raimondo, M.A., Miceli, G.N. and Scopelliti, I. (2020), "Effects of au naturel packaging colors on willingness to pay for healthy food", Psychology and Marketing, Vol. 37 No. 7 , pp. 913-927.

Miraballes, M., Fiszman, S., Gámbaro, A. and Varela, P. (2014), "Consumer perceptions of satiating and meal replacement bars, built up from cues in packaging information, health claims and nutritional claims", Food Research International, Vol. 64, pp. 456-464.

Nordin, N. and Selke, S. (2010), "Social aspect of sustainable packaging", Packaging Technology and Science, Vol. 23 No. 6, pp. 317-326.

Olsen, M.C., Slotegraaf, R.J. and Chandukala, S.R. (2014), "Green claims and message frames: how green new products change brand attitude", Journal of Marketing, Vol. 78 No. 5, pp. 119-137.

Pancer, E., McShane, L. and Noseworthy, T.J. (2017), "Isolated environmental cues and product efficacy penalties: the color green and eco-labels", Journal of Business Ethics, Vol. 143 No. 1, pp. 159-177.

Pinson, C. (1986), “An implicit product theory approach to consumers' inferential judgments about products", International Journal of Research in Marketing, Vol. 3 No. 1, pp. 19-38.

Piqueras-Fiszman, B. and Spence, C. (2012), "The weight of the container influences expected satiety, perceived density, and subsequent expected fullness", Appetite, Vol. 58 No. 2, pp. 559-562.

Prakash, G. and Pathak, P. (2017), "Intention to buy eco-friendly packaged products among young consumers of India: a study on developing nation”, Journal of Cleaner Production, Vol. 141, pp. 385-393.

Raghunathan, R., Naylor, R.W. and Hoyer, W.D. (2006), "The unhealthy=tasty intuition and its effects on taste inferences, enjoyment, and choice of food products", Journal of Marketing, Vol. 70 No. 4, pp. $170-184$.

Rees, W., Tremma, O. and Manning, L. (2019), "Sustainability cues on packaging: the influence of recognition on purchasing behavior", Journal of Cleaner Production, Vol. 235, pp. 841-853.

Rokka, J. and Uusitalo, L. (2008), "Preference for green packaging in consumer product choices-do consumers care?", International Journal of Consumer Studies, Vol. 32 No. 5, pp. 516-525.

Rundh, B. (2005), "The multi-faceted dimension of packaging: marketing logistic or marketing tool?”, British Food Journal, Vol. 107 No. 9, pp. 670-84.

Schuldt, J.P., Muller, D. and Schwarz, N. (2012), "The 'fair trade' effect: health halos from social ethics claims", Social Psychological and Personality Science, Vol. 3 No. 5, pp. 581-589.

Scott, M.L., Nowlis, S.M., Mandel, N. and Morales, A.C. (2008), "The effects of reduced food size and package size on the consumption behavior of restrained and unrestrained eaters", Journal of Consumer Research, Vol. 35 No. 3, pp. 391-405.

Seo, J.Y. and Scammon, D.L. (2017), "Do green packages lead to misperceptions? The influence of package colors on consumers' perceptions of brands with environmental claims", Marketing Letters, Vol. 28 No. 3, pp. 357-369.

Steenis, N.D., van der Lans, I.A., van Herpen, E. and van Trijp, H.C. (2018), "Effects of sustainable design strategies on consumer preferences for redesigned packaging", Journal of Cleaner Production, Vol. 205, pp. 854-865. 
Steenis, N.D., van Herpen, E., van der Lans, I.A., Ligthart, T.N. and van Trijp, H.C. (2017), “Consumer response to packaging design: the role of packaging materials and graphics in sustainability perceptions and product evaluations", Journal of Cleaner Production, Vol. 162, pp. 286-298.

Suher, J., Raghunathan, R. and Hoyer, W.D. (2016), "Eating healthy or feeling empty? How the 'healthy=less filling' intuition influences satiety", Journal of the Association for Consumer Research, Vol. 1 No. 1, pp. 26-40.

Sundar, A. and Kardes, F.R. (2015), "The role of perceived variability and the health halo effect in nutritional inference and consumption", Psychology and Marketing, Vol. 32 No. 5, pp. 512-521.

The satiating power of sustainability

Tal, A. and Wansink, B. (2015), "An apple a day brings more apples your way: healthy samples prime healthier choices", Psychology and Marketing, Vol. 32 No. 5, pp. 575-584.

Talukdar, D. and Lindsey, C. (2013), "To buy or not to buy: consumers' demand response patterns for healthy versus unhealthy food", Journal of Marketing, Vol. 77 No. 2, pp. 124-138.

Underwood, R.L. and Klein, N.M. (2002), "Packaging as brand communication: effects of product pictures on consumer responses to the package and brand", Journal of Marketing Theory and Practice, Vol. 10 No. 4, pp. 58-68.

Van Birgelen, M., Semeijn, J. and Keicher, M. (2009), "Packaging and proenvironmental consumption behavior: investigating purchase and disposal decisions for beverages", Environment and Behavior, Vol. 41 No. 1, pp. 125-146.

Vila-Lopez, N. and Küster-Boluda, I. (2020), “A bibliometric analysis on packaging research: towards sustainable and healthy packages", British Food Journal, Vol. 123 No. 2, pp. 684-701.

Wansink, B. and Chandon, P. (2006), “Can 'low-fat' nutrition labels lead to obesity?”, Journal of Marketing Research, Vol. 43 No. 4, pp. 605-617.

Wansink, B., van Ittersum, K. and Painter, J.E. (2004), "How diet and health labels influence taste and satiation”, Journal of Food Science, Vol. 69 No. 9, pp. S340-S346.

White, K., Lin, L., Dahl, D.W. and Ritchie, R.J. (2016), "When do consumers avoid imperfections? Superficial packaging damage as a contamination cue", Journal of Marketing Research, Vol. 53 No. 1, pp. 110-123.

(The Appendix follows overleaf) 
BFJ

123,13

176

\section{Appendix 1}

Stimuli and description used in Study 2

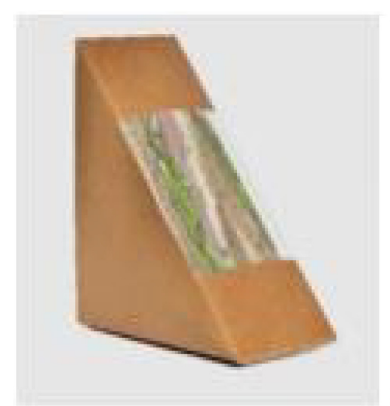

INGREDIENTS:
Integral bread,
Smoked Turkey,
Salad, Low Fat
cheese

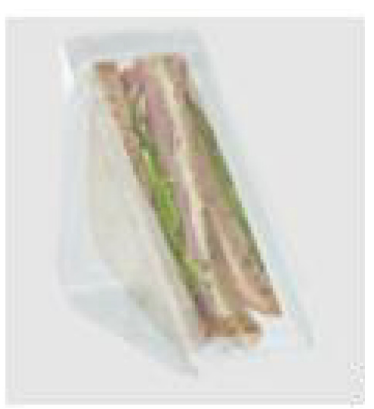

INGREDIENTS:

Integral bread, Smoked Turkey, Salad, Low Fat cheese 

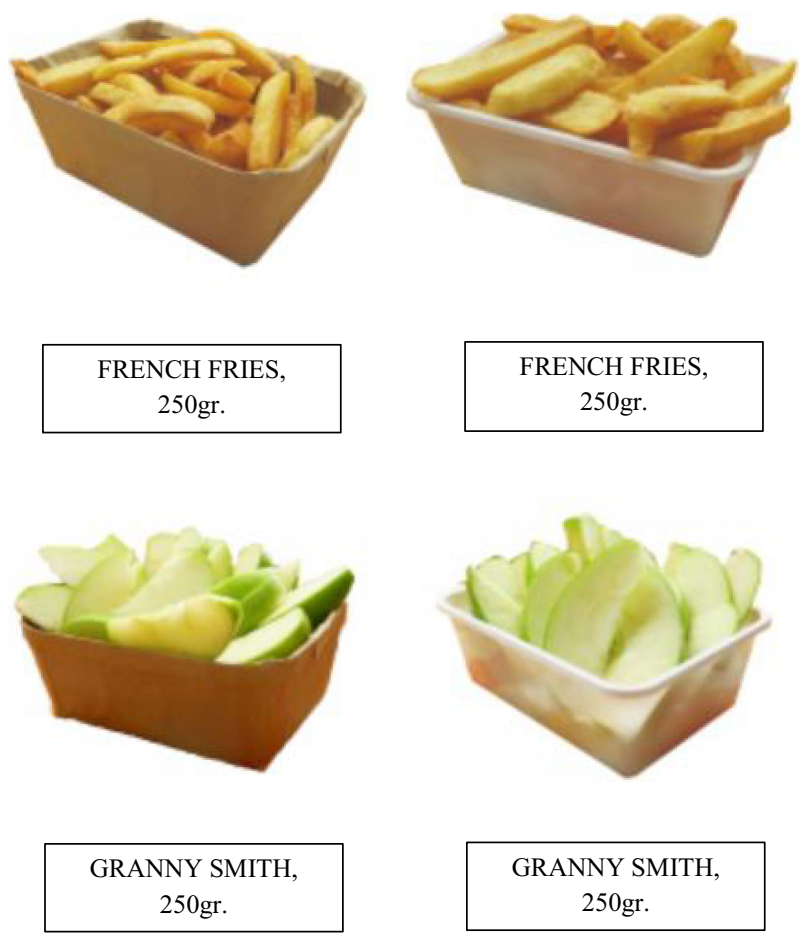

\section{Corresponding author}

Carmela Donato can be contacted at: donatoc@luiss.it

For instructions on how to order reprints of this article, please visit our website: www.emeraldgrouppublishing.com/licensing/reprints.htm Or contact us for further details: permissions@emeraldinsight.com 